\title{
Service quality attributes in urban bus services: the experience of Belem-Para/Brazil
}

\author{
M. Tobias ${ }^{1}$, J. Waisman ${ }^{2}$ \& H. de Paiva $\mathrm{Jr}^{3}$ \\ ${ }^{I}$ Department of Transportation Engineering, \\ Universidade Federa do Pará, Brazil, Universidade da Amazônia, Brazil \\ ${ }^{2}$ Department of Transportation Engineering, \\ Escola Politécnica da Univesidade de São Paulo, Brazil, \\ Sistran Engenharia \\ ${ }^{3}$ Centro Universitário Belas Artes de São Paulo, Brazil, \\ Athina Engenharia
}

\begin{abstract}
The city of Belem, in Brazil's northern region, is known as the gateway of the Amazon and is also capital of the Para state and part of a metropolitan region.

In the last 10 years, deep changes in the metropolitan socioeconomic and land use structures have led to a decrease in bus ridership. This is due to congestion jams in bus corridors and continuous quality deterioration of bus services.

A survey was done to determine and evaluate which service attributes influence users' opinions that allow them to have a negative image of bus transport. Data were obtained through a home survey (500 households) applied to bus users in order to identify their socioeconomic status, trip patterns, service evaluation and both favourable and unfavourable opinions towards bus services. A detailed analysis of the results permits the identification of the most important existing problems and shortcomings and gives subsidy to a comprehensive diagnosis of the whole bus transport system.

Keywords: urban bus, users behaviour, image and opinion.
\end{abstract}

\section{Introduction}

The city of Belém, in Brazil's northern region, is known as the gateway of the Amazon. (See Figure 1.) 


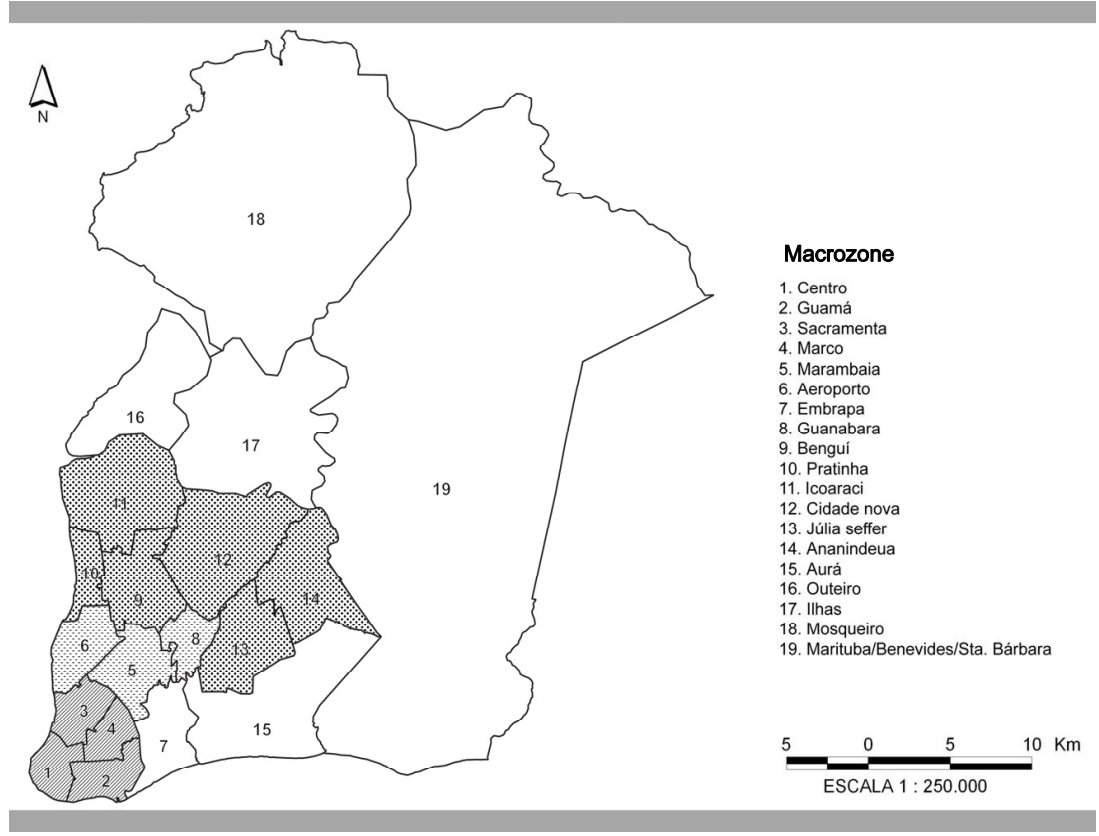

Figure 1: $\quad$ Study area.

Capital of the Para state, with 1.3 million people, Belém is located in a peninsula at Guajará bay, and comprises two sectors: the continent and the islands. Belem is also part of a metropolitan region that includes 4 more municipalities (Ananindeua, Marituba, Benevides and Santa Bárbara do Pará) comprising 1.8 million inhabitants.

The Belem Metropolitan Region (BMR) economic structure is based on the third sector (commerce / services / government) with $91 \%$ of total jobs, with onethird of all jobs concentrated at Belem's CBD and its surroundings.

The average income of $50 \%$ of the metropolitan region is between $\mathrm{R} \$ 211,00$ (US\$ 125.00) and R \$ 630,00 (US\$ 370.00).

Belem has lived its most glorious days in the second half of the $19^{\text {th }}$ century, during the rubber boom. Then, after a long period of stagnation, the city has recovered its growth with the construction of a highway connecting it to the Brazilian capital, Brasilia.

The area around the old port ("Old City") is still the most important trip generation area within the city. The main transport corridors leave this area towards the hinterland, but in a non-continuous form due to the existence of the "Institutional Belt" formed by large properties owned by the army and other public entities.

Despite these facts, the continental areas went through a process of intense growth due to the implementation of large housing units and also of irregular low-income constructions. 
In the last 10 years, deep changes in the BMR's socioeconomic structure have led to changes in urban mobility due to the population growth, the population average income decrease, increasing auto ownership rates, increasing bus services supply in the main corridors, the lack in investments both in new corridors as well improvements in the existing ones and a disorganized process of urban expansion in the peripheral areas and high building construction in the CBD (Tobias [1]).

As a result, bus trips share within the modal split has diminished, mainly because of continuous quality of services deterioration.

Recent studies show the record of 4.0 million daily trips in the BMR and modal split is: bus, 44.6\%; bicycle / on foot, 42.0\%; and auto, 13.4\%. Bus share was $59.2 \%$ ten years ago.

BMR public transport services are structured according 3 sub-systems:

- $\quad$ intermunicipal buses connecting Belem to other cities in the metropolitan region;

- $\quad$ Belem local (municipal) buses;

- $\quad$ other local (municipal) buses; and

- $\quad$ water transportation connecting Belem to Marajo Island.

\section{Transport services as a consumer good}

Transport users are consumers of a given type of product / service, and it is known that consumer's behaviour can be influenced by personality, motivations and perceptions as well as by political, socioeconomic and cultural factors among others.

The decision making process does not end with the product / service purchase. After that a comparison between expectations regarding the product / service and its performance occurs. Service use provides a set of knowledge and feelings, which will influence the consumer's image about the product / service. And, product / service performance evaluation is closely tied to product / service characteristics and contingencies.

In transport, different alternatives are offered to users through different specifications (stimuli), such as: technology / transport mode, level of service, price, and temporal and spatial availability. On the other hand, user decision making will be influenced by his / her personal characteristics, former experiences and displacement needs.

Then, transport users perception on services rendered results from the evaluation of the performance of a set of service attributes, which occur due to interactions between users and the transport mode during the process of service production (Parasuraman [2]).

Many authors have presented a set of relevant attributes in user's quality evaluation. One of them (Lima [3]) includes: 


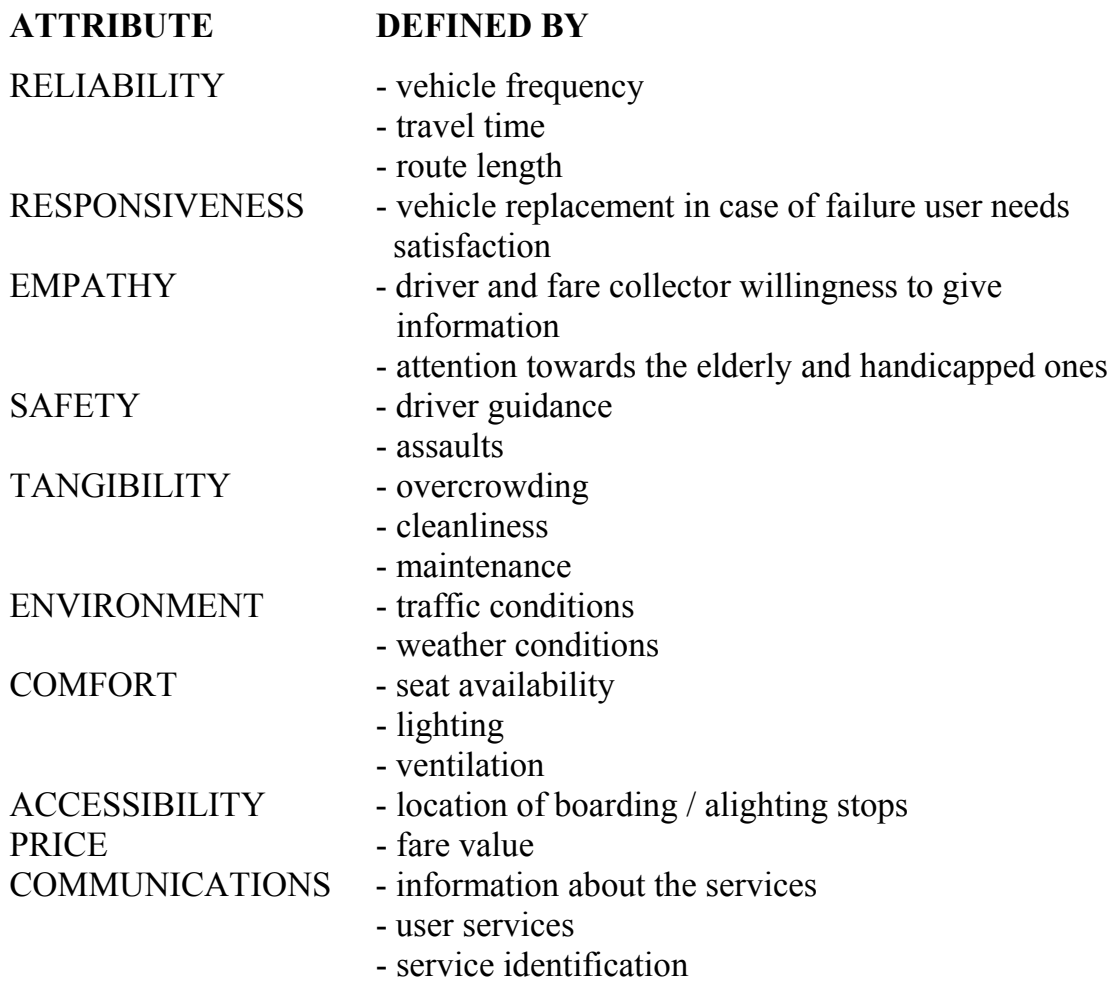

According to de Paiva Jr [4] the transport behaviour of the second most important segment of urban transport user of Belém is sensitive to attitudinal variables, so this paper intends to study the BMR bus transport user's perception and the construction of an image of the services.

\section{Study case}

A home survey was conceived to investigate users' opinion on the most relevant quality attributes and their influence on modal choice.

A sample of 500 households in 14 homogeneous macro-areas (Figure 1) was selected within BMR's most populated areas ( $94 \%$ of households) and the survey was conducted through visits and interviews along a period of 6 months.

Specific questionnaires were applied to bus users (questions: frequency of daily / weekly trips and trip purposes, means of payment; average trip duration; quality and fare evaluation; perception of attributes of quality of services; and socioeconomic status).

A specific questionnaire was also applied to handicapped persons users of the bus services (questions: frequency of daily / weekly trips and trip duration, means of payment, average trip duration, quality and fare evaluation, perception of quality attributes of services. 
In the end, a total number of 1.278 valid questionnaires had been obtained, according to the following distribution: bus users' interviews - 1.239; and handicapped persons' interviews -39 .

Data collected were intended to:

- $\quad$ identify user's socioeconomic status (age, gender, income, instruction);

- $\quad$ identify trip patterns (trip frequency, purpose and duration);

- analyse trip attributes (reliability, responsiveness, empathy, safety, tangibility, environment, comfort, accessibility, price, communications).

\subsection{Survey results}

The survey data processing and analysis indicated the following for the bus transport system.

\section{Bus users}

- users socioeconomic status:

- male $-49,6 \%$

- female $-50,4 \%$

- age $-52,9 \%$ between 20 and 39 years

- education - 79,6\% with 8 schooling years

- average family monthly income: US\$ 490.00

- average daily trips frequency: $69,7 \%$ on 5 week days

- average work trip per week: $48 \%$ all week days

- average school trip per week: $48,6 \%$ on 5 week days

- $\quad$ tariff payment: $46,6 \%$ full fare with cash; $32,7 \%$ student fare (half price)

- $\quad$ average travel time (work trips): $47,8 \%$ less than $35 \mathrm{~min}$

- $\quad$ average travel time (school trips): 59,4\% less than $35 \mathrm{~min}$

- quality evaluation:

- very good / good: $12,9 \%$

- regular :39,3\%

- $\quad$ bad / very bad $: 27,8 \%$

- $\quad$ transport fare evaluation:

- very expensive / expensive: $54,9 \%$

- adequate : $31,3 \%$

- cheap : $9,5 \%$

- gratuity : $4,3 \%$

Construction of an image about services rendered departs from opinions stated by users. Data collected from the field survey showed 5.395 opinions about quality attributes, being 1.450 favourable and 3.945 un-favourable.

Bus favourable opinions:

$\begin{array}{lll}\text { ACCESSIBILITY } & \text { - accessibility is good } & : 22,6 \% \\ \text { PRICE } & \text { - student fare } & : 19,9 \% \\ & \text { - fare is cheap } & : 8,1 \% \\ \text { RESPONSIVENESS } & \text { - no transfer needed } & : 14,7 \% \\ \text { RELIABILITY } & \text { - enough service supply: } 13,0 \% \\ & \text { - short waiting time } & : 12,5 \% \\ \text { COMFORT } & \text { - always find a seat } & : 9,2 \%\end{array}$


Bus unfavourable opinions:

$\begin{array}{lll}\text { EMPATHY } & \text { - driver / fare collector is impolite: } & 20,7 \% \\ \text { PRICE } & \text { - fare is expensive } & : 17,0 \% \\ \text { COMFORT } & \text { - buses are crowded } & : 15,0 \% \\ \text { TANGIBILITY } & \text { - buses are dirty } & : 13,0 \% \\ \text { SAFETY } & \text { - buses are not safe } & : 11,7 \% \\ \text { RESPONSIVENESS } & \text { - services supply is insufficient } & : 11,6 \% \\ \text { RELIABILITY } & \text { - high waiting times } & : 11,0 \%\end{array}$

As it can be seen, most $(65,3 \%)$ of the favourable opinions expressed refer to attributes of accessibility, price and responsiveness. Most $(65,7 \%)$ of the unfavourable opinions expressed refer to attributes of empathy, price, comfort and tangibility.

Except for price that appears in both sets of opinions, one could observe that, in a general way, physical and operational system characteristics are well praised by the users, while empathy, comfort and tangibility are the most criticized ones.

Data obtained for handicapped persons users of bus services show almost the same pattern observed for the average bus user: age between 20 and 49 years, third sector workers $(31,4 \%)$ and low-income $(57,1 \%) .91 \%$ commute 2 times a day and $68,6 \%$ evaluate bus quality as very bad / bad.

Opinions expressed by handicapped persons point that drivers / charge collectors are impolite $(22,9 \%)$, boarding / alighting from vehicles is difficult $(13,3 \%)$; space between seats is narrow $(9,5 \%)$.

\section{Disaggregate analysis}

A disaggregated analysis of data collected for each of 13 homogeneous (according to socioeconomic and land use patterns) macro-zones was then conducted to evaluate the influence of these factors on users behavior as well the distance from these locations to the CBD.

A close look into the performance of bus services in the study area (Figure 1) shows multiples quality dimensions to be considered and multiple cases to compare. Give the complexity of this task, the Chernoff faces technique (Hair et al. [5]) was applied to resume quickly the main quality aspects and compare the BMR macro-zones at the same time.

The first step was the correlation of the quality dimensions with the Chernoff faces characteristics (Table 1). So each face characteristic varies with the percent of users satisfied or unsatisfied with the respective quality dimensions of the bus service of each macro-zone (Tobias and Peixeira [1]). As there are 13 macrozones and each one has 12 bus service quality attributes, there are $13 \times 12$ statistics to be analyzed and compared. Applying the Chernoff faces, the problem is simplified to an intuitive judgment of 13 faces which can be grouped into similar subsets.

The 13 Chernoff faces of each macro-zone surveyed are shown in Figure 2, plus three standard faces as an absolute reference to help the analysis. These standard faces are located in the bottom right of the figure. And each one 
exemplify how looks like a 100\% satisfied user's Chernoff face, a 50\% satisfied user's Chernoff face and a $100 \%$ unsatisfied user's Chernoff face.

For example, considering the users safety perception issue represented by the pupil's position (Table 1), the reader can see that the "happiest face" looks to right, the "apathetic face" looks toward the reader and the "angriest face" looks to left. Another example is overall satisfaction represented by the mouth curvature. When the satisfied users proportion is higher, the curve concavity is turned up; otherwise it is flat or turned down according to the dissatisfaction proportion.

Table 1: Chernoff technique.

\begin{tabular}{cll}
\hline Chernoff face characteristic & Quality dimension \\
\hline 1. & Face with & Overcrowding \\
2. Length of nose & Seat availability; \\
3. & Position of pupils & Safety \\
& & Driver guidance; \\
& Assauts \\
4. Length of eyebrow & Politeness \\
& & Drive and fare collector willingness to give \\
& & information; \\
5. Nose with & Attention towards the elderly and handicapped ones. \\
& Spotless \\
6. Length of nose & Cleanliness; maintenance \\
7. & Height of eyebrows & Vehicle replacement in case of failure \\
8. Curvature of mouth & Trans-ship \\
9. Eccentricity of eyes & Overall satisfaction \\
10. Length of mouth & General service quality \\
11. Position of center of mouth & Waiting time \\
12. Angle of eyebrow & Accessibility to the system \\
\hline
\end{tabular}

Absolute evaluation of bus service quality in RMB

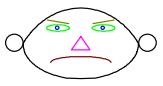

Centro

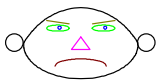

Marambaia

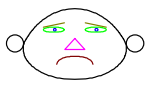

Pratinha

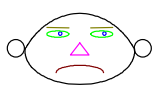

Ananindeua

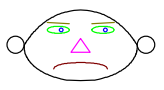

Guama

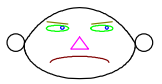

Aeroporto

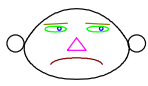

Icoaraci

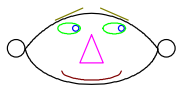

$100 \%$ Satisfied

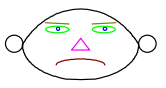

Sacramaento

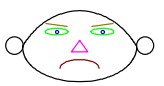

Guanabara

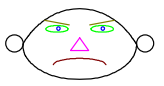

Cidade Nova

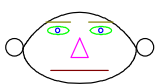

$50 \%$ Satisfied
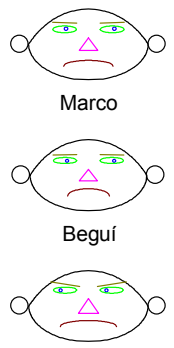

Júlia Seffer

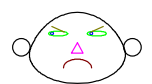

100\% Unsatisfied

LEGEND: face/w = LOTACAO, nose $/ \mathrm{l}=\mathrm{SENTADO}$, mouth/cent = ONDEQUER, mouth/curv = SERVBOM, mouth $/$ = PASSAPER, eyes/ecc = N_ESPERA, pupils $/$ pos $=$ SEGURO, eyebrows $/ \mathrm{h}=$ TRANSBOR, eyebrows/ang $=$ PASBARAT, eyebrows $/ I=$ EDUCACAO, nose $/ w=$ LIMPEZA,

Figure 2: $\quad$ Chernoff faces for absolute evaluation (STATSOFT [6]). 
There are two figures of Chernoff faces, one to represent the BMR bus service image compared to an absolute quality standard achieved when $100 \%$ of users surveyed declare to be satisfied with all quality attributes, and another one to represent the relative BMR service image calculated based in the best proportion of satisfied users for each attribute of all macro-zones. So, the benchmark for Figure 2 is variable, because there is no macro-zone with the best performance in all 12 attributes. For example, the macro-zones Centro and Aeroporto are the benchmarking of accessibility and the Guamá is the benchmark of the destination availability perception. Figure 2 gives an overall image of bus service of BMR and Figure 3 highlights the strengths and weakness of each macro-zone.

The conclusion of Figure 2 is that image of all the bus system of the surveyed area in the BMR is indeed very bad, because all face expressions are closer to the "angriest face".

Relative evaluation of bus service quality in RMB
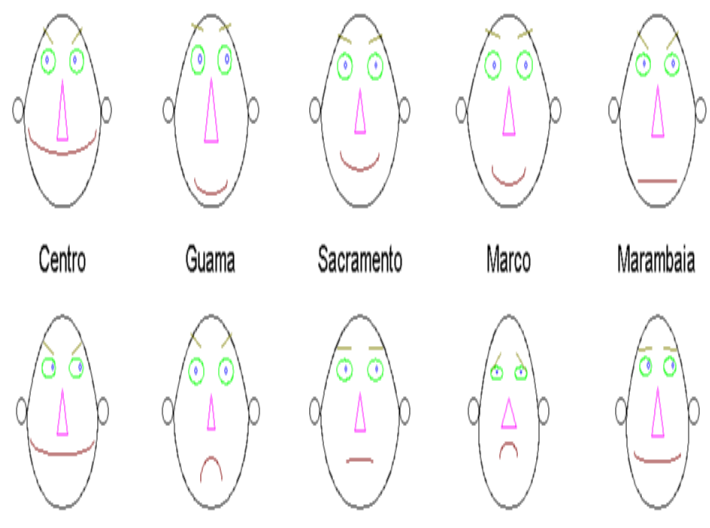

Sacramentito

Marco

Marambala

Aeroponto
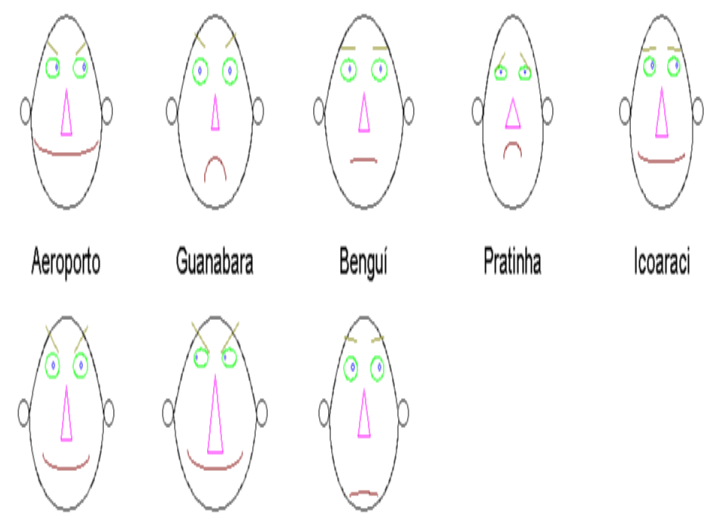

Benguí

Pretiinha

|coaraci

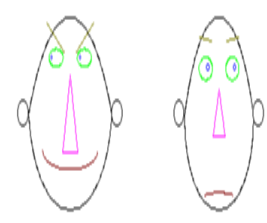

Cidade Nova Juilia Seffer Anarindela

LEGEND: facelW= LOTACAO, nosell = SENTADO, mouthlcent = ONDEQUER,

mouthlourv $=$ SERVBOM, mouthl $=$ PASSPPER, eyeslecc =N_ESPERA, Mvpilspos = SEGURO, eyebrowsh = TRANSBOR, eyebrows/ang = PASBARAT, eyebrows : = EDCCACAO, noselW = LMPEZA,

Figure 3: $\quad$ Chernoff faces for relative evaluation (STATSOFT [6]). 
Observing Figure 3, it is possible to group the macro-zones into three expressions types: Type 1 - represented by macro-zones: Centro, Aeroporto, Cidade Nova and Júlia Seffer; Type 2 - represented by macro-zones: Guama, Sacramento and Macro; Type 3 - represented by macro-zone: Benguí, Ananindeua and Icoarací.

There is also Guanabara, Pratinha and Marambaia, but there expressions are unique, showing particular service problems.

Type 1 is characterized by a relative better overall image, accessibility to the system, but lower destination availability and a relative expensive fare.

Type 2 is characterized by a relative good overall image and destination availability in spite of the lower accessibility to the system and the relative expensive fare.

Type 3 is less happy with the overall image, but users do not think that the fare cost too much.

Finally, there is Guanabara clearly unhappy with service and fare, Marambaia very upset with the fare, and Pratinha sad with the overall service, lack of accessibility, crowded vehicles and destination availability, but users are the only ones happy with the bus fare.

Of course there are many other attributes to be accounted however these attributes do not call for more attention because they do not show a significant change among the macro-zones surveyed.

One last aspect to be considered is the spatial distribution of the transport infrastructure. Comparing the geographical distribution of the Chernoff faces there is no clear relation between the user perceptions and their macro-zone residence, but it seems that the central residents have a better image of the overall service and are more critical of the fare while the suburban residents have a worst image and are less critical of the fare.

\section{Conclusions}

The results presented somehow explain the reduction in bus patronage in the BMR. It can be said that bus use is actually influenced by the system structural problems and high-valued fares vis a vis a low income population.

Over the years, users have consolidated a negative image towards the bus services and in spite of the increase in services supply, new and old market needs remained dissatisfied.

Innovation is very poor in the services rendered, here included operation and technological aspects as well the pricing policy.

Decreasing average commercial speeds and increasing total travel times have been a continuous trend in the last years, due to traffic jams in the main bus corridors. This led to losses both in productivity and service quality.

On the other hand, the existing regulatory agency lacks either legal or political instruments, as well as operational and monitoring infrastructure, to intervene and improve the present situation.

As a result, required actions are slow (or even do not happen) and services control and supervision is almost nonexistent. 


\section{References}

[1] TOBIAS, M.S.G. and PEIXEIRA, A.P.D. Análise de alterações espaciais da mobilidade por ônibus em Belém, Pa. Congresso Luso - Brasileiro para o Planejamento Urbano, Regional, Integrado e Sustentável (Anais Eletrônicos), 2005.

[2] PARASURAMAN, A. et al. A conceptual model of service quality and its implications for future research. Journal of Marketing, 49, p. 41-50,1985.

[3] LIMA JR., O.F. Qualidade em serviços de transportes: conceituação e procedimento para diagnóstico. PhD Thesis. Universidade de São Paulo, Escola Politécnica, São Paulo, 1995.

[4] PAIVA JR., H. Segmentação e modelagem comportamental de usuários dos serviços de transporte urbanos brasileiros. PhD Thesis. Universidade de São Paulo, Escola Politécnica, 2006.

[5] HAIR, J. F.; ANDERSON, R. E.; TATHAM, R. L.; BLACK, W. C. Análise multivariada de dados. Tradução Adonai Schlup Sant'Anna; Anselmo Chaves Neto. $5^{\text {a }}$ Edição, Porto Alegre: Bookman, 2005. 593

[6] STATSOFT. STATISTICA 99 Edition for Windows. Tulsa, OK: StatSoft, Inc., 2300 East 14th Street, Tulsa, OK 74104, phone: (918) 749-1119, fax: (918) 749-2217, email: info@statsoft.com, WEB: http://www.statsoft.com. 1999. Statistical applicative. 